\title{
Analytical Semi-Empirical Model for the Prediction of Products Yields at the Fast Pyrolysis of Waste Palm Oil
}

\begin{abstract}
ANA MARIA SIVRIU ${ }^{1}$, DOINITA ROXANA TARPAN², CLAUDIA-IRINA KONCSAG ${ }^{2 *}$, ALINA MONICA MARES ${ }^{1}$, COSMIN J INESCU ${ }^{3}$ 'University Politehnica of Bucharest, Faculty of Applied Chemistry and Materials Science, 1-7 Gh. Polizu Str., 011061, Bucharest, Romania

2University Ovidius of Constanta, Faculty of Applied Science and Engineering, 124 Mamaia Blvd., 900527, Constanta Romania ${ }^{3}$ Politehnica University of Bucharest, Faculty of Mechanic and Mecatronic, 313 Splaiul Independentei, 060042, Bucharest, Romania

The interest for vegetable oils, as a source of fuels and chemicals, boosted in the last two decades amid concerns related to oil depletion. The fast pyrolysis is a process of industrial consequences. In the present study, original experimental data in fast pyrolysis are processed in order to find the parameters of ASEM- an analytical semi-empirical model developed by the Clean Combustion Technology Laboratory (CCTL), University of Florida. The parameters, constants and coefficients of the model equation ( $w, T, D, p$ and $q)$, were calculated for each main product with satisfactory accuracy and results were compared with other authors'. The results were discussed based on similarities and differences between slow and fast pyrolysis. The conclusion was that ASEM is a valid model which can be applied with confidence in very different process conditions.
\end{abstract}

Keywords: Fast pyrolysis, vegetable oil, analytical semi-empirical model (ASEM), yield prediction

Vegetable oils, in particular non-edible and waste oils, count for a renewable source of fuels. Best known as raw materials for biodiesel production, vegetable oils were also raw in the pyrolysis process for gasoline-like fuel obtaining, during WWI and WWII, in absence of petroleum reserves [1]. The interest for vegetable oils, as a source of fuels, boosted in the last two decades amid concerns related to fossil fuels depletion. The goal of many research studies was to obtain gasoline [2], kerosene-like [3] or Diesel-like [4] fuels, but lighter hydrocarbon and syngas are also desirable products. For this, the following types of thermal treatments can be applied to vegetable oils: thermal catalytical cracking [5, 6], hydrocracking [7] and pyrolysis [1]. Defined as a thermal treatment of materials containing carbon and hydrogen, in absence of air, pyrolysis is largely used in case of biomass $[8,9]$.

Pyrolysis of vegetable oils can be controlled to obtain ideal products. Thermodynamics calculations showed that the cleavage of $\mathrm{C}-\mathrm{O}$ bond starts at $288^{\circ} \mathrm{C}$ while the â bond scission, taking $\mathrm{C}=\mathrm{C}$ bond as á bond, occurs at about $400^{\circ} \mathrm{C}$ [10]. Higher yields of light compounds in pyrolysis gas and especially high yields of olefins are obtained at higher temperatures and shorter residence times, in the process of fast pyrolysis [11].

Predicting these yields is a practical goal for those intending to scale up a process for obtaining intermediate compounds for petrochemistry. This study is a continuation of research in the field $[12,13,14]$ with reference to the industrial applications of the process.

\section{Experimental part}

ASEM developed by the Clean Combustion Technology Laboratory (CCTL)

By systematizing a very large number of experimental data, the Clean Combustion Technology Laboratory (CCTL), University of Florida, has developed an analytical semiempirical model (ASEM), as an alternative to the prediction of pyrolysis products yields through kinetic modeling. With a small number of adjustable parameters, simple equations represent a robust model describing the response to thermochemical treatment of a large palette of waste solids, containing $\mathrm{C}, \mathrm{H}$ and $\mathrm{O}$ [14]. The ASEM model represents product yields, wt. \%, by the function:

$$
Y(T)=w\left[L\left(T: T_{0}, D\right)\right]^{p}\left[F\left(T: T_{0}, D\right)\right]^{q}(1)
$$

where $Y(T)$ is a temperature only function for asymptotic yields (wt. \%) of slow pyrolysis or fast pyrolysis. Otherwise, the yields (wt. \%) also depend on residence time.

In equation (1), L [(T:T), D] is a logistic function called learning curve (eq.2) and $\mathrm{F}[(\mathrm{T}: \mathrm{T}, \mathrm{D}]$ is its complement $(F=1-L)$ (eq.3). They are curves describing originally the progress and the regress of the learning process with training. The analogy with other processes (economics, manufacture and marketing) resulted from finding that normally a model's performance improves as the number of experimental data increases. As for the thermal cracking process, for each product five parameters are assigned $\left(w, T_{0}, D, p, q\right)$ to represent its yield versus temperature profile. When $q=0$ and hence $[F(T)]^{q}=1$, the parameter $w$, represents the maximum yield. For $p=1, T$ represents the $50 \%$ rise point of the learning curve and $D$ fixes the slope of the curve at this point [15].

$$
\begin{aligned}
& L\left(T: T_{0}, D\right)=\frac{1}{\left[1+\exp \left(\frac{T_{0}-T}{D}\right)\right]} \\
& F\left(T: T_{0}, D\right)=\frac{1}{\left[1+\exp \left(\frac{T-T_{0}}{D}\right)\right]}
\end{aligned}
$$

According to Sadramelli and Green [14], while w, pand $q$ result from regression of experimental data, $T$ and $D$ can be chosen by fitting the yield of a dominant product of one hydrocarbon class, with the parameters $p=1$ and $q=0$.

The model is so robust that not only interpolation between the experimental limits is correct but extrapolation beyond upper limit is possible with good fitting results. For example, experimental data for the pyrolysis of polyethylene are available up to $850^{\circ} \mathrm{C}[16,17]$ but prediction of yields was extrapolated to $1000^{\circ} \mathrm{C}$ in 
conformity with constrains for carbon, hydrogen and oxygen mass balance.

After development of the model, a series of works were dedicated to find the 5 parameters for other feedstock such as vegetable oils, Sadramelli and Green [14] processing extensive experimental data obtained by Idem et al. [18] at the University of Saskatchewan, Canada. Unlike the majority of studies performed in batch reactors, these experiments were carried out in tubular reactors in continuous operation. The model was applied in veryslow pyrolysis conditions (residence time approx. $1.5 \mathrm{~h}-7 \mathrm{~h}$ ) and that has justified the use of the ASEM without time factor.

By considering fast pyrolysis of industrial consequence, in the present study, our own experimental data in fast pyrolysis will be processed in order to find the parameters of ASEM, for representative products obtained from waste palm oil.

Determination of ASEM parameters for fast pyrolysis of waste palm oil

Experimental data were obtained in a tubular reactor, in continuous operation. A detailed presentation of equipment and test procedure was included in a previous paper [19].

The feedstock is cooking palm oil with iodine number of $5.07 \mathrm{gl} / 100 \mathrm{~g}$ oil, as a measure of the degradation degree of the oil. The waste cooking palm oil was thermally treated at temperatures in range of $555-630^{\circ} \mathrm{C}$, at $0.049 \mathrm{~h}$ residence time, in absence of air or a carrier gas. Yields of products are calculated from chromatographic composition of the gas and the total gas yield; they are listed in table 1 . Traces of oxygen and nitrogen may proceed from imperfect sealing or manipulation of gas sample bags. The rest of compounds resulted in the thermal cracking of triglycerides.

Following the indications of Sadramelli and Green [14], the compounds were systematized on classes: olefins, paraffins and permanent gases $\left(\mathrm{H}_{2} \mathrm{CO}\right.$ and $\left.\mathrm{CO}_{2}\right)$, then the first two parameters were assigned for all compounds yields: $T$ and $D$.

Parametres $T$ and $D$ were determined by fitting the yield of a dominant product of olefins class (the ethylene), with the parameters $p=1$ and $q=0$. This resulted in $T=743 \mathrm{~K}$ (approx. $470^{\circ} \mathrm{C}$ ) and $D=298 \mathrm{~K}$ (approx. $20^{\circ} \mathrm{C}$ ). Then $T_{0}$ and
Table 1

YIELDS OF GASEOUS PRODUCTS (\% wt.) AS A FUNCTION OF TEMPERATURE AT THE FAST PYROLYSIS OF WASTE PALM OIL (RESIDENCE TIME $t=0.049 \mathrm{~h}$ )

\begin{tabular}{|c|c|c|c|}
\hline \multirow{2}{*}{ Compounds } & \multicolumn{3}{|c|}{ Temperature, $\mathrm{T},{ }^{\circ} \mathrm{C}$} \\
\hline & 555 & 580 & 630 \\
\hline Hydrogen & 0.09 & 0.14 & 0.15 \\
\hline $\mathrm{CO}$ & 7.60 & 7.32 & 7.28 \\
\hline $\mathrm{CO} 2$ & 8.56 & 9.03 & $7.21^{-}$ \\
\hline Oxygene & 0.09 & 0.13 & 0.15 \\
\hline Nitrogen & 0.31 & 0.44 & 0.53 \\
\hline Methane & 2.33 & 3.05 & 3.67 \\
\hline Ethane & 3.47 & 3.97 & 4.40 \\
\hline Propane & 2.02 & 1.90 & 1.76 \\
\hline Butanes & 0.97 & 0.88 & 0.71 \\
\hline Pentanes & 0.46 & 0.46 & 0.36 \\
\hline Alkanes $\mathrm{C}_{6}-\mathrm{C}_{10}$ & 0.37 & 0.17 & 0.19 \\
\hline Ethylene & 7.62 & 8.47 & 10.00 \\
\hline Propylene & 6.02 & 6.94 & 7.91 \\
\hline 1-Butene & 2.72 & 2.65 & 2.91 \\
\hline 2-Butene & 0.92 & 1.85 & 1.78 \\
\hline i-Butene & 0.13 & 0.18 & 0.21 \\
\hline Butadiene & 1.14 & 1.19 & 1.58 \\
\hline Cyclo-C5,C6 & 0.09 & 0.12 & 0.12 \\
\hline Benzene $\left(\mathrm{C}_{6} \mathrm{H}_{6}\right)$ & $0.33^{-}$ & 0.32 & $0.58^{-1}$ \\
\hline $\begin{array}{c}\text { Total gas yield, } \\
\% w t\end{array}$ & 45.24 & 49.20 & 51.73 \\
\hline
\end{tabular}

$D$ remained the same tor all the other products, as they are the constants of the model.

The parameters $p$ and $q$ were adopted for all products, in first instance, from the model fitted for canola oil [14] and $w$ was determined by regression of original experimental data; if necessary, $p$ and $q$ were recalculated for better fitting of predicted values to experimental data. Results of the model's fitting are shown in tables 2-4 for different gaseous compounds, together with predicted values of products yields compared with experimental data, resulting in residuals.

Table 2

ASEM PARAMETERS FOR OLEFINS $\left(\mathrm{T}_{0}=470^{\circ} \mathrm{C}, \mathrm{D}=20^{\circ} \mathrm{C}\right)$

\begin{tabular}{|c|c|c|c|c|c|c|}
\hline \multirow{2}{*}{ Compound } & \multicolumn{3}{|c|}{ Parameters of model } & \multicolumn{2}{|c|}{ Field, wt. \% } & \multirow{2}{*}{$\begin{array}{c}\text { Residuals } \\
Y_{\text {(onodicted) }}-Y_{\text {(copl) }}\end{array}$} \\
\hline & $w$ & $p$ & $q$ & $Y_{\text {(predictoded) }}$ & $Y_{\text {(exporimentand) }}$ & \\
\hline \multirow{3}{*}{ Ethylene } & 15.0 & 1 & 0 & 8.56 & 7.64 & 0.92 \\
\hline & 15.0 & 1 & 0 & 8.87 & 8.46 & 0.41 \\
\hline & 15.0 & 1 & 0 & 9.47 & 9.99 & -0.52 \\
\hline \multirow{3}{*}{ Propylene } & 12 & 1 & 0.03 & 6.68 & 6.01 & 0.67 \\
\hline & 12 & 1 & 0.03 & 6.91 & 6.94 & -0.03 \\
\hline & 12 & 1 & 0.03 & 7.35 & 7.93 & -0.58 \\
\hline \multirow{3}{*}{ Butenes } & 10 & 1.5 & 0.04 & 4.17 & 3.77 & 0.40 \\
\hline & 10 & 1.5 & 0.04 & 4.39 & 4.68 & -0.29 \\
\hline & 10 & 1.5 & 0.04 & 4.82 & 4.90 & -0.08 \\
\hline \multirow{3}{*}{ Butadiene } & 3 & 1.5 & 0.04 & 1.25 & 1.14 & 0.11 \\
\hline & 3 & 1.5 & 0.04 & 1.32 & 1.19 & 0.13 \\
\hline & 3 & 1.5 & 0.04 & 1.45 & 1.58 & -0.13 \\
\hline
\end{tabular}


Table 3

ASEM PARAMETERS FOR PARRAFINS $\left(\mathrm{T}_{0}=470^{\circ} \mathrm{C}, \mathrm{D}=20^{\circ} \mathrm{C}\right)$

\begin{tabular}{|c|c|c|c|c|c|c|}
\hline \multirow{2}{*}{ Compound } & \multicolumn{3}{|c|}{ Parameters of model } & \multicolumn{2}{|c|}{ Field, wt. \% } & \multirow{2}{*}{$\begin{array}{c}\text { Residuals } \\
Y_{\text {(predicted) }}-Y_{(\text {(exp.) }}\end{array}$} \\
\hline & $w$ & $p$ & $q$ & $\boldsymbol{Y}_{\text {(oredicted) }}$ & $\boldsymbol{Y}_{\text {(exporimental) }}$ & \\
\hline \multirow{3}{*}{ Methane } & 5.5 & 1 & 0.04 & 3.04 & 2.33 & 0.70 \\
\hline & 5.5 & 1 & 0.04 & 3.14 & 3.04 & 0.09 \\
\hline & 5.5 & 1 & 0.04 & 3.34 & 4.1 & -0.76 \\
\hline \multirow{3}{*}{ Ethane } & 6.5 & 0.8 & 0.02 & 4.08 & 3.47 & 0.61 \\
\hline & 6.5 & 0.8 & 0.02 & 4.19 & 3.97 & 0.23 \\
\hline & 6.5 & 0.8 & 0.02 & 4.41 & 4.92 & -0.51 \\
\hline \multirow{3}{*}{ Propane } & 2.8 & 0.6 & 0.03 & 1.95 & 2.02 & -0.07 \\
\hline & 2.8 & 0.6 & 0.03 & 1.99 & 1.90 & 0.09 \\
\hline & 2.8 & 0.6 & 0.03 & 2.06 & 1.96 & 0.10 \\
\hline \multirow{3}{*}{ Butanes } & 1.5 & 0.9 & 0.04 & 0.88 & 0.97 & -0.09 \\
\hline & 1.5 & 0.9 & 0.04 & 0.90 & 0.88 & 0.02 \\
\hline & 1.5 & 0.9 & 0.04 & 0.95 & 0.79 & 0.16 \\
\hline
\end{tabular}

Table 4

ASEM PARAMETERS FOR PERMANENT GASES $\left(\mathrm{T}_{0}=470^{\circ} \mathrm{C}, \mathrm{D}=20^{\circ} \mathrm{C}\right)$

\begin{tabular}{|c|c|c|c|c|c|c|}
\hline \multirow{2}{*}{ Compound } & \multicolumn{3}{|c|}{ Parameters of model } & \multicolumn{2}{|c|}{ Yield, wt. \% } & \multirow{2}{*}{$\begin{array}{c}\text { Residuals } \\
\left.Y_{\text {(preaticted) }}-Y_{(\text {(exp) }}\right)\end{array}$} \\
\hline & $w$ & $p$ & $q$ & $Y_{\text {(orealicted) }}$ & $\boldsymbol{Y}_{\text {(expoerimental) }}$ & \\
\hline \multirow{3}{*}{ Hydrogen } & 0.24 & 1.4 & -0.1 & 0.12 & 0.09 & 0.03 \\
\hline & 0.24 & 1.4 & -0.1 & 0.13 & 0.14 & -0.01 \\
\hline & 0.24 & 1.4 & -0.1 & 0.14 & 0.17 & -0.03 \\
\hline \multirow{3}{*}{$\mathrm{CO}$} & 20 & 2 & -0.1 & 7.09 & 7.59 & -0.50 \\
\hline & 20 & 2 & -0.1 & 7.65 & 7.33 & 0.32 \\
\hline & 20 & 2 & -0.1 & 8.80 & 8.12 & 0.68 \\
\hline \multirow{3}{*}{$\mathrm{CO} 2$} & 11 & 0.2 & 0.2 & 8.30 & 8.54 & -0.24 \\
\hline & 11 & 0.2 & 0.2 & 8.28 & 9.05 & -0.77 \\
\hline & 11 & 0.2 & 0.2 & 8.22 & 8.06 & 0.15 \\
\hline
\end{tabular}

\section{Results and discussions}

The five parameters of the model found and presented in Tables (2-4) - $w, T, D, p$ and $q$ - proved a good fitting of predicted values with experimental data. The highest residuals in terms of relative errors were in case of hydrogen $( \pm 24.1 \%)$, but the majority o relative errors were smaller than $10 \%$. Anyway, the yield of hydrogen is low and without importance for industrial recovery, so errors won't affect the practical goal of this work.

It is interesting to observe that model's parameters $p$ and $q$ were the same as determined by Sadramelli and Green [14]. This confirms that their approach- a statistical processing of a very large number of experimental data and exponential curves fitting correlated inside every class of compounds- was right.

The parameters $D$ and $T_{0}$, are different from findings in [14], $T=375^{\circ} \mathrm{C}$ and $\mathrm{D}=40^{\circ} \mathrm{C}$, but fact is that their experimental data were obtained in very slow pyrolysis process, since in the present study it was fast pyrolysis where residence time is short and the raw material needs higher temperature in order to start cracking, and the all appearance of the learning curves is different.

The parameter $w$ is the product maximum yield obtainable from palm oil in fast pyrolysis. The values of the parameter $w$, are very different from those found in slow pyrolysis. For example, $w$ for ethylene resulted here $w=15$ since it was $w=25$ in [14] and for propylene $w$ was 12 , comparing with 15.5; lower values of $w$ for smaller molecules (ethylene, propylene, methane, ethane) and higher values than in [14] for heavier compounds: for propane $w=2.8$ comparing with $w=1.33$, for butenes $w=$ 10 comparing with $w=0.8$. This can be explained by the short residence time in the present experiment leading to fewer cracking reactions, thus resulting in longer molecule chains in the effluent. So, in fast pyrolysis, the yields of ethylene and propylene are expected to be lower, but butenes and butadiene are in higher yield than in case of slow pyrolysis.

\section{Conclusions}

Waste vegetable oils count for a sustainable source of valuable chemicals. Olefins are of particular interest and research studies were dedicated for their production through thermal cracking of oils. Despite the large number of experimental data, few mathematical models for the prediction of products yields were developed. The goal of this study was to find the parameters of a previously developed analytical semi-empirical model (ASEM), in order to predict the gaseous products yields at the fast pyrolysis of waste palm oil.

The parameters of the ASEM, constants and coefficients $\left(w, T_{0^{\prime}} D, p\right.$ and $\left.q\right)$ of the model equation were calculated for each main product with satisfactory accuracy and results were compared with other authors'. The parameters found here were checked for the said raw material in the range of $550-630^{\circ} \mathrm{C}$ and residence time $0.049 \mathrm{~h}$ and may 
be extrapolated at shorter residence time and a few dozen Celsius degrees beyond temperature limits, with caution. The results were discussed based on similarities and differences between slow and fast pyrolysis. The main conclusion was that ASEM is a valid model which can be applied with confidence in very different process conditions. It may serve to scale up the process of fast pyrolysis of vegetable oils with the scope of obtaining intermediate compounds for petrochemistry.

\section{References}

1. WIGGERS, V.R., MEIER, H.F., WISNIEWSKI, JR. A., CHIVANGA BARROS, A.A., WOLF MACIEL, M.R., Biores. Techn., 100, 2009, p.6570. 2. SHIRAZI, Y., VIAMAJALA, S., VARANASI, S., Applied Energy, 179, 2016, p.755-764.

3. DA SILVA ALMEIDA, H.; CORREA, O. A.; EID, J. G.; et all., J. Anal. Appl. Pyrol, 120, 2016, p.126.

4. CRAIG, W., SOVERAN, D., Canadian Patent 1, 313, 200, 1993.

5. RAO, T., MALLESWARA, V., DUPAIN, X., MAKKEE, M., Micropor Mesopor Mat, 164, 2012, p.148.

6. TIAN H., LI C., YANG C., SHAN H., Chinese Journal of Chemical Engineering, 16, 2008, p.394.
7. ELLER, Z., VARGA, Z., HANCSOK, J., Fuel, 182, 2016, p.713.

8. PARVULESCU, O. C., DOBRE, T., CEATRA, L., et all., Rev. Chim. (Bucharest), 62, no. 1, 2011, p. 89.

9. PARVULESCU, O.C., GAVRILA, A.I., DOBRE, T., et all., Rev. Chim. (Bucharest), 67, no. 11, 2016, p.2254.

10. ZHENYI, C., XING, J., SHUYUAN, L., LI, L., Energ Sour, 26, 2004, p.849.

11. ZAMOSTNY, P., BELOHLAV, Z., SMIDRKAL, J., Resour Conserv Recy, 59, 2012, p.47.

12. GREEN A., CHAUBE, R., Turbo Expo, Atlanta, USA, 2003, p. 1.

13. GREEN, A.E.S. BELL, S.M., Proceedings of the 14th North American Waste to Energy Conference, Tampa, USA, NAWTEC14, 2006, p.149.

14. SADRAMELI S.M, GREEN, A.E.S., J. Anal. Appl. Pyrol., 78, 2007, p. 445.

15. GREEN, A.E.S., FENG J., J. Anal. Appl. Pyrol., 76 (1-2), 2006, p.60. 16. MASTRAL, F. L., ESPERANZA, E., GARCIA, P., JUSTE, M., J. Anal. Appl. Pyrol., 63, 2002, p. 1.

17. MASTRAL, F. J., ESPERANZA, E., BERRUCO, C., JUSTE, M., J. Anal. Appl. Pyrol., 70, 2003, p. 1.

18. IDEM, R.O., KATIKANENI, S.P.R., BAKHSHI, N.N., Energ Fuel, 10, 1996, p.1150.

19. SIVRIU, A.M., KONCSAG, C., JINESCU, G., MARE a , A.M., UPB Scientific Bulletin, series B: Chemistry and Material Sciences, 79, 2017, p.67.

Manuscript received: 23.02.2018 